\title{
THE PROBLEMATIC OF BUDGET IMPLEMENTATION IN NIGERIA: A STUDY OF DELTA STATE GOVERNMENT
}

\section{Kelly Bryan Ovie Ejumudo}

Novena University, Ogume, Nigeria

E-mail: drkellypaulovieejumudo@yahoo.com

\section{Tobi Becky Ejumudo}

Department of Business Administration and Management,

School of Management and Technology Obiaruku, Delta State, Nigeria

E-mail: ejumudotobi@yahoo.com

\begin{abstract}
This study examines the problematic of budget implementation in Nigeria using Delta State as a case study. The design of the study was descriptive survey. The population of the study comprised of 2383 senior staff in the Delta State Ministry of Basic and Secondary Education, Ministry of Economic Planning, Ministry of Works, Ministry of Housing and Ministry of Finance. The sample of the study consisted of 350 senior staff drawn from level 10-16 using stratified and simple random techniques. The instruments used for data collection was budget implementation questionnaire. The data were analyzed using mean rating and chi-square. The findings of the study revealed that there is significant relationship between politics of accommodation, poor commitment, compromised budget monitoring, culture of corruption and budget implementation in Delta State. The study also recommended among others that approved budgets should be religiously implemented without considering or accommodating the personal or selfish interests of different stakeholders in the political system, there should be genuine and high-level commitment to the execution of budgets after their approval so that such budgetary allocations and provisions can translate into concrete development in all the envisaged sectors, and there should be an efficient and effective monitoring of approved budgetary projects as well as zero tolerance for corruption.
\end{abstract}

Key-words: problematic, budget, implementation, Nigeria and Delta State 


\section{Introduction}

Globally, budgeting which an integral part of public or government is financing is the nerve-center of governance at all levels. This is particularly because of its central role in the determination of government revenue and expenditure. It therefore follows that without budgeting; the multi-layered levels of government cannot raise revenue and engage in public expenditure. Budgeting is therefore at the heart of the execution of government policy and the actualization of its various programmes, projects, operations and activities. Moreover, as far as budgeting is concerned with the allocation of funds to different sectors of government, it is critical to sectorial and national development. Also, in so far as the generation of such funds and their allocation for governmental activities has to be authorized and checked, budgeting is a key instrument of public financing management (Adetayo 2017).

It is instructive to note that budgeting encapsulates budget preparation, authorization, implementation, accounting and auditing. Implicitly, budgeting does not terminate at preparation stage; rather, it covers the above range of functioned activities in such a manner and fashion that the process can be explicitly describe as cyclical. As a consequence, budget planning should be accompanied with appropriate implementation after authorization by the relevant legislative authorities (Plebn 2009). The truism of this assertion is evident in the fact that budget plans cannot be translated into concrete realities regardless of how beautifully crafted they are. In fact, budget plans are dormant until they are activated through implementation into the envisioned tangible projects, programmes, operations and activities.

The importance and critical role that budgeting is expected to play in the development of all nations largely explains why several scholars and experts have devoted a growing attention to the academic discourse on the topical issue. For instance, Ianna (2018) examined budget implementation and governance in Nigeria and contended that poor governance results to poor budget implementation which occurs when the desired result on the target beneficiaries is not actualized. Onho \& Zayol (2017) also explored budgeting and budgetary control in the public sector using ministry of finance in Benue State as a case study. The findings of the study revealed that budgeting and budgetary control in the public sector is weak and despite the effort of government, budget and budgetary control has failed because of dependence on federation account, untrained budget staff, non-adherence to budgetary control measures, corruption, inflation and political environment.

In a similar vein, Onyiah, Ezeamama, Ugwu and Mgbodile (2016) studied the impact of budget implementation and control reforms of the Federal 
Government of Nigeria and the findings showed that poor project conceptualization, design or planning practices by Ministries, Departments and Agencies (MDAs) resulted into low resources management. Ekhator and Chima (2015) equally investigated the efficacy of budget as instrument of realizing the goal of public policy and the study indicated that the factors responsible for the failure in budget implementation were delay in preparation, late submission and appropriation, cumbersome bureaucratic process of securing release of funds, short fall in revenue, poor implementation plan and above all corruption.

However, the contention of this study is that at the heart of effective and result oriented budget implementation are proper budget planning, genuine commitment to budget plans, budget monitoring and control as well as executive-legislative synergy and collaboration. All the same, budget implementation in Nigeria has over the years been constrained and plagued by factors including politics of accommodation, poor budget implementation, compromised budget monitoring and the culture of corruption. These factors have not only constituted a cog in the wheel of budget implementation, they have equally negatively affected the translation of budget plans into action programmes and projects. As a consequence, there exist commonly gaps between approved budget plans and actual implementation in such a way that the needs, yearnings and aspirations as well as the expectations of the Nigerian states and its teeming citizens are largely not met.

\section{Operationalization of the research}

\subsection{Statement of the Problem}

In the face of the globally acceptable and recognized importance of budget planning, budget approval, budget implementation, budget control and budget evaluation as critical aspects or stages the functional governmental budgetary activity, it appears that budget implementation in Nigeria has over the decades faced several challenges. Such challenges have arguably affected the effectiveness and quality of budget implementation as well as the act actualization of budgets plan in the context of government programmes and projects. The contention of this study is that the problematic of budget implementation in Nigeria, particularly in Delta State, is the product of politics of accommodation, poor budget implementation, compromised budget monitoring and the culture of corruption. 


\subsection{Objectives of the Study}

The general objective of the study is to examine the problematic of budget implementation in Delta State Government, while the specific objectives are to:

1. Assess if there is any relationship between politics of accommodation (the dysfunctional system whereby the stakeholders of the executive and legislative arms of government protect and accommodate each other's interest) and budget implementation in Delta State Government.

2. Examine if there is any relationship between poor commitment to budget implementation and budget implementation in Delta State Government.

3. Investigate if there is any relationship between compromised budget monitoring and budget implementation in Delta State Government.

4. Assess if there is any relationship between culture of corruption and budget implementation in Delta State Government.

\subsection{Research Questions}

The following research questions were raised to guide the study:

1. To what extent has politics of accommodation (the dysfunctional system whereby the stakeholders of the executive and legislative arms of government protect and accommodate each other's interest) affected budget implementation in Delta State?

2. To what extent has poor commitment to budget implementation affected budget implementation in Delta State?

3. To what extent has compromised budget monitoring affected budget implementation in Delta State?

4. To what extent has culture of corruption affected budget implementation in Delta State?

\subsection{Research Hypotheses}

The following null hypotheses were formulated for testing at 0.05 level of significance:

1. There is no significant relationship between politics of accommodation (the dysfunctional system whereby the stakeholders of the executive and legislative arms of government protect and accommodate each other's interest) and budget implementation in Delta State Government.

2. There is no significant relationship between poor commitment to budget implementation and budget implementation in Delta State Government.

3. There is no significant relationship between compromised budget monitoring and budget implementation in Delta State Government. 
4. There is no significant relationship between culture of corruption and budget implementation in Delta State Government.

\section{Empirical Review on Budget Implementation}

Nwaorgu, (2018) investigates the effect of dominant individuals on budget implementations in Nigeria. The methodology used in the study is content analysis method. The literature and empirical review reveal that the activities of dominant individuals range from manipulation of budget items before and after approval of annual estimate: embezzlement and fraudulent activities: lack of proper budgeting processes is responsible for the failure of budget in Nigeria. The recommendations therefore include the need for budget reform in Nigeria. Budget should be based on thorough evaluation of revenue and needs and the issue of probity, transparency and accountability should be properly addressed in the budget process. The implication of findings includes high level of youth unemployment, poverty and corruption as well as causing underdevelopment of Nigeria.

Ianna (2018) examine budget implementation and governance in Nigeria. In any polity, be it developed, developing or under-developed, the idea of governance conjures a theoretical undertone of the social contract and the common good which budget implementation is expected to assure. This paper contends that poor governance results to poor budget implementation which occurs when the desired result on the target beneficiaries is not actualized. The paper after analyzing several ways through which governance can improve budget implementation in Nigeria, went further to recommend among other things, that all the parties concerned especially the target beneficiaries should be involved at the formulation stage of the budget so as to accommodate all inputs. This will go a long way in providing the needed commitment by all parties who will see the budget as originating from them.

Onho \& Zayol (2017) explored budgeting and budgetary control in the public sector using ministry of finance in Benue State as a case study. To ascertain the effectiveness of budgets control and the problems affecting budgeting and budgetary control, the writers used literature review as their main source of data using ministry of Finance, Makurdi as a case study and also made use of personal observations. The writers found that budgeting and budgetary control in the public sector is weak and despite the effort of government, budget and budgetary control has failed because of dependence on federation account, untrained budget staff, non-adherence to budgetary control measures, corruption, inflation and political environment. The author recommended among others that there is a need for budget culture in the 
public sector, sharpening the budget monitoring and implementation procedures in the public sector, sustaining greater accountability and transparency and making the need for budgeting realistic and not just a formality.

Adekunle (2016) assess the factors responsible for budget failure in Nigeria. To achieve this broad goal, the econometric model of Analysis of variance (ANOVA) regression test was employed for analysis and time series data span from 2010 to 2015. The finding shows that budget in the public sector of Nigeria has almost become a ritual or a yearly affair which though good in content but without appreciable result. The issue of budget failure in Nigeria is of concern to the general public. The dependent variable was represented by budgeted amount for the selected period, while the independent variable were gross domestic product (GDP) which represent the economic planning, and poverty index represents social development. The results revealed that budgeting has a strong relationship with Nigerian GDP. The results further showed a strong relationship between budgeting and poverty index (PI). The study recommends that government should enact an enabling law that will ensure the workability of its budgets according to plans and increase the proportion of capital expenditure to recurrent expenditure so that the budget can have impact on economic planning and social development; budget preparation should start in good time; more capital expenditure should be included in the budget plan to speed increase in the value of social development; money not accessed during the period of budget implementation could be moved to a more viable project.

Onyiah, Ezeamama, Ugwu and Mgbodile (2016) studied the impact of budget implementation and control reforms of the Federal Government of Nigeria with a view to analyzing their impact on resource management, level of productivity and efficiency and personnel and overhead costs in Nigeria. The study employed ex-post facto descriptive research design. The respondents comprised of Accountants and Economists who are in the federal civil service in Enugu state. The primary data were collected with the aid of a structured 5-point likert scale questionnaires. Secondary data were generated from journals, and other scholarly publications. Three Hypotheses were formulated and tested in this study. The questionnaires were distributed to a sample size of 308 from a population of 1338 using Taro Yamane (1967) formula while Analysis of Variance (ANOVA) was also employed to test the hypotheses. The findings showed that poor project conceptualization, design or planning practices by Ministries, Departments and Agencies (MDAs) resulted into low resources management. Respondents also perceived that there is no significant reduction in the personnel and 
overhead cost budgets allocated to the public service. The study concludes that the effectiveness of Medium Term Revenue Framework and Medium Term Expenditure Framework can be achieved through budget discipline. Participatory monitoring and assessment of government projects by host community-members and identifications of opportunities/Challenges for Government Services are recommended.

Ekhator and Chima (2015) investigated the budget as instrument of realizing the goal of public policy. Using data generated from secondary sources, it was found that the goals of most policies were not accomplished in Nigeria due to incessant budget failure at the stage of the formulation and implementation. Critical among the factors responsible for the failure were; delay in preparation, late submission and appropriation, cumbersome bureaucratic process of securing release of funds, short fall in revenue, poor implementation plan and above all corruption. Consequently, the paper suggested the way forward which includes; effective monitoring, timely submission of the budget to legislature by the presidency, discouragement of unnecessary lobbying of National Assembly by MDAs and avoidance of temptations of allocating huge amount to new projects while the on-going projects are starved of funds.

Asogwa (2015) assessed the measures that would stem the tide of low budget implementation in Nigeria public sector using South-East geopolitical zone of Anambra, Enugu, Abia, Imo, Ebonyi and Enugu States as case study. To achieve this aim, conceptual, historical and theoretical framework was adopted in literature review. Three research hypotheses were formulated and tested in empirical setting using chi-square (x2) statistical tools. Findings of the study revealed that poor budgetary implementation in the Nigerian public sector have had significant negative effect on the Nigerian economy. The study showed that factors such as late presentation and passage of appropriation bills, delay in release of funds for capital projects, ineffective planning, corruption in the public sector amongst others have contributed to low budgetary implementation in Nigeria. The study concluded by highlighting that effective planning and the adoption of responsibility accounting system will assist in enhancing budget implementation in Nigeria.

Njokwu (2015) assessment of the impact of budget implementation in the attainment of the Millennium Development Goals (MDGs) - Related programmes in Anambra State, with the sole objective of examining how the state's policy and spending autonomy significantly enhance the achievement of the MDGs - related programmes. It is based on the above objective that the study hypothesized that if there is effective implementation of budget in Anambra State, and then there is the likelihood of achieving the MDGs - 
related programmes in the State. Another hypothesis of the study was that the spending patterns of the state negatively affect achievement of MDGs related programmes in the state. In the course of the study, we applied descriptive research methodology in making use of primary and secondary data collection techniques. For the primary source, In-depth Individual Interviews (IDIs) was used. Purposive sampling technique was used because MDGs are sector-specific from where a sample size of 250 was drawn. These were the core leadership of ministries, departments and agencies (MDAs) of the State. In the analysis of the data collected, appropriate statistical techniques were adopted in the study to test the study's hypotheses. Some of these statistical techniques were percentages, correlation coefficient and Canonical Correlation Analysis (CCA). The use of these methods in analyzing the study's $x$ objectives and hypotheses give rise to the findings of the study. The findings border on the fact that the state's budget implementation has significantly positive correlation with the MDGs - related programmes of the state in education and health sectors but more of the achievement was in the later and that myriad of factors among which was that the state lacked strong institutional framework needed to effectively mobilize and utilize public resources for effective service delivery for the MDGs. It is from these findings and conclusion that the study made some suggestions on how to improve public spending for effective and efficient delivery of MDGs - related programmes. One of the proffered solutions includes the need for institutional capacity building in Nigerian states. With these suggestions properly implemented, the study believes that, the 2015 target could be met.

Oniore (2014) investigated budget implementation and economic development in Delta State from 1991 to 2010. The study was prompted by the low level of economic development in the state. The study was guided by three research objectives which apparently transmitted into three research questions. The study is descriptive in nature. The data were analyzed using these statistical tools; simple percentage, graphs, and pie charts. Primary and Secondary data were sourced for this study. The major findings of the study are on the factors which have been responsible for budgets failures in the state, which includes budget indiscipline, lack of accountability, nonconsideration of reasonable suggestions from interest groups while preparing the budget, inadequate monitoring instruments, political instability, non-usage of accurate data, inconsistent economic planning and policies etc. In order to arrest such unpleasant situations, the following recommendations were advanced; strict observance of budget discipline, creation of enabling operational environment, putting in place of adequate supervisory machinery, positive consideration of reasonable suggestions 
from interest groups, introduction of remedial measures at the appropriate time and the use of accurate data in the cause of preparing the state future budget(s). In conclusion the State budgets have not been fully implemented since the creation of the state. However, the study reveals that the budgets have made meaningful contribution to the socio-economic and political development of the state.

Achi (2013) investigated poor budgetary performance: Causes and implications for development. The research was a case study and data were sourced from government workers using a questionnaire. A total of 150 questionnaires were distributed and 119 retrieved. Data obtain were analyzed using descriptive and empirical analyses. The descriptive analysis employs the use of tables, percentages and charts to describe the characteristics of the responses in the questionnaires. The empirical analysis employs the use of multiple regressions of the ordinary least square and covariance and correlation analyses. The results of the analyses show that factors such as poor planning, fraudulent manipulation, lack of adequate professional knowledge, delay in passage of budget, late release of fund are all responsible for poor budget performance in the state. The implication is that it discourages investors due to poor condition of the state infrastructures, it reduces the standard of living of the people of the state, and it slows down economic development through wasteful spending, extra budgetary spending and debt accumulation.

Oke (2013) investigated the effect of budget implementation on the Nigerian economic growth and provides panacea to the problem of budget allocation and its implementation. To achieve this broad goal, the econometric model of ordinary least square (OLS) regression test was employed for analysis and time series data span from 1993 to 2010 was considered. Budget in the public sector of Nigeria has almost become a ritual or a yearly affair which though good in content but without appreciable result. The issue of budget implementation has long been a source of concern to the public and also considering the important impetus of budget implementation on economic growth and development in Nigeria. The dependent variable was provided by gross domestic product (GDP), while the independent variables were public total expenditure (PEX), public recurrent expenditure (PRE), public capital expenditure (PCE) and external debt (EXD). The results revealed that budget implementation has a positive effect impact on Nigeria economic growth. The results further showed a positive relationship between GDP and public total expenditure (PEX), public recurrent expenditure (PRE), public capital expenditure, external debt (EXD), while public capital expenditure (PCE) shows a negative relationship to GDP. The study 
recommends that government should enact on enabling law that will ensure the workability of its budgets according to plans and increase the proportion of capital expenditure to recurrent expenditure so that the budget can have growth and development inducement among others.

Ugoh \& Ukpere (2009) investigated the problems and prospects of budgeting and budget implementation in local government system in Nigeria Local Government has historically provided services of importance to its citizens in rural and urban areas in Nigeria. These services include provision of basic amenities like water, roads, health facilities, education, etc. Of late, the role of local government in providing these services has attracted public concern. Furthermore, it has generated national crisis as a result of increasing rate of poverty among the rural people. Some scholars view this development to poor budgeting and implementation while others associate it to the federal and state government's interference. In this work, we are focused on budgeting as it relates to the local government in Nigeria. The paper therefore, examines the sources of finance of the local government and its autonomy considering the nature of fiscal federalism in the country. It also tries to investigate the difficulties in budget process and implementation in Nigeria with emphasis on the local government.

\section{Presentation of Results}

Research Question One:

To what extent has politics of accommodation affected budget implementation in Delta State?

Table 1: Mean rating showing the extent to which politics of accommodation has affected budget implementation

\begin{tabular}{|l|l|l|l|l|l|}
\hline S/N & A & SA & D & SD & X \\
\hline $\mathbf{1}$ & 192 & 170 & 54 & 200 & $\mathbf{1 . 7 9}$ \\
\hline $\mathbf{2}$ & 154 & 358 & 195 & 96 & $\mathbf{2 . 3 3}$ \\
\hline $\mathbf{3}$ & 179 & 154 & 207 & 80 & $\mathbf{1 . 7 9}$ \\
\hline $\mathbf{4}$ & 179 & 172 & 75 & 220 & $\mathbf{1 . 8 7}$ \\
\hline $\mathbf{5}$ & 179 & 154 & 222 & 60 & $\mathbf{1 . 7 8}$ \\
\hline $\begin{array}{l}\text { Grand } \\
\text { mean }\end{array}$ & & & & & $\mathbf{1 . 9 1}$ \\
\hline
\end{tabular}

Source: Field Work 2018

Criterion Mean $=2.5$ 
Table 1 shows a grand mean of 1.91 and a criterion mean of 2.50 . Since the grand mean is less than the criterion mean, it implies that majority of the respondents agreed that politics of accommodation has affected budget implementation. Hence, it can be concluded that the Uduagha-led government projects in the works, housing as well as basic and secondary education sector of the 2008 to 2015 Delta State was affected by politics of accommodation.

Hypothesis $1\left(\mathrm{Ho}_{1}\right)$

There is no significant relationship between politics of accommodation and budget implementation in Delta State Government.

Table 2: Chi-square analysis of questionnaire for the relationship between politics of accommodation and budget implementation

\begin{tabular}{|c|c|c|c|c|c|c|c|}
\hline Items & SA/A & $\mathrm{SD} / \mathrm{D}$ & Total & Df & $\mathrm{X}^{2}$-cal. & $\mathrm{X}^{2}$-cri. & Decision \\
\hline 1 & 80 & 20 & 345 & \multirow{5}{*}{3} & \multirow{5}{*}{161.19} & \multirow{5}{*}{7.82} & \multirow{5}{*}{$\begin{array}{l}\mathrm{Ho}_{1} \text { is } \\
\text { Rejected }\end{array}$} \\
\hline 2 & 74 & 26 & 345 & & & & \\
\hline 3 & 74 & 26 & 345 & & & & \\
\hline 4 & 76 & 24 & 345 & & & & \\
\hline 5 & 74 & 26 & 345 & & & & \\
\hline
\end{tabular}

Source: Field Work 2018

$\mathrm{P}>0.05$

In table 2 above, with alpha level of 0.05 , the degree of freedom (DF) of 3 , the critical value is 7.82 while calculated value is 161.19 . Since the calculated value is greater than the critical value, the null hypothesis is therefore rejected. This shows that there is a significant relationship between politics of accommodation and budget implementation in Delta State.

Research Question Two:

To what extent has poor commitment to budget implementation affected budget implementation in Delta State?

Table 3: Mean rating showing the extent to which poor commitment has affected budget implementation

\begin{tabular}{|l|l|l|l|l|l|}
\hline S/N & A & SA & D & SD & X \\
\hline $\mathbf{1}$ & 150 & 240 & 180 & 60 & $\mathbf{1 . 8 3}$ \\
\hline $\mathbf{2}$ & 160 & 280 & 180 & 60 & $\mathbf{1 . 9 7}$ \\
\hline $\mathbf{3}$ & 150 & 300 & 90 & 60 & $\mathbf{1 . 7 4}$ \\
\hline $\mathbf{4}$ & 130 & 280 & 180 & 60 & $\mathbf{1 . 8 8}$ \\
\hline $\mathbf{5}$ & 100 & 300 & 210 & 100 & $\mathbf{2 . 0 6}$ \\
\hline
\end{tabular}




\begin{tabular}{|l|l|l|l|l|l|}
\hline $\begin{array}{l}\text { Grand } \\
\text { mean }\end{array}$ & & & & & 1.89 \\
\hline
\end{tabular}

Source: Field Work 2018 Criterion Mean $=2.5$

Table 4 shows a grand mean of 1.89 and a criterion mean of 2.50. Since the grand mean is less than the criterion mean, it implies that majority of the respondents agreed that poor commitment has affected budget implementation in Delta State. Hence, it can be concluded that the Uduaghaled government projects in the works, housing as well as basic and secondary education sector of the 2008 to 2015 Delta State was affected by poor commitment to a low extent.

Hypothesis $2\left(\mathrm{Ho}_{2}\right)$

There is no significant relationship between poor commitment to budget implementation and budget implementation in Delta State.

Table 5: Chi-square analysis of questionnaire for the relationship between poor commitment and budget implementation

\begin{tabular}{|c|c|c|c|c|c|c|c|}
\hline Items & $\mathrm{SA} / \mathrm{A}$ & SD/D & Total & Df & $\mathrm{X}^{2}$-cal. & $\mathrm{X}^{2}$-cri. & Decision \\
\hline 1 & 78 & 22 & 345 & \multirow{5}{*}{3} & \multirow{5}{*}{145.99} & \multirow{5}{*}{7.82} & \multirow{5}{*}{$\begin{array}{l}\mathrm{Ho}_{2} \quad \text { is } \\
\text { Rejected }\end{array}$} \\
\hline 2 & 87 & 13 & 345 & & & & \\
\hline 3 & 87 & 13 & 345 & & & & \\
\hline 4 & 78 & 22 & 345 & & & & \\
\hline 5 & 72 & 28 & 345 & & & & \\
\hline
\end{tabular}

Source: Field Work 2018

$\mathrm{P}>0.05$

In table 5 above, with alpha level of 0.05 , the degree of freedom (DF) of 3 , the critical value is 7.82 while calculated value is 145.99 . Since the calculated value is greater than the critical value, the null hypothesis is therefore rejected. This means that there is a significant relationship between poor commitment and budget implementation in Delta State.

Research Question Four:

To what extent has compromised budget monitoring affected budget implementation in Delta State? 
Table 6: Mean rating of the response of sampled staff on the relationship between compromised budget monitoring and budget implementation

\begin{tabular}{|l|l|l|l|l|l|}
\hline $\mathbf{S} / \mathbf{N}$ & $\mathbf{A}$ & SA & $\mathbf{D}$ & SD & $\mathbf{X}$ \\
\hline $\mathbf{1}$ & 100 & 240 & 240 & 180 & $\mathbf{2 . 2 0}$ \\
\hline $\mathbf{2}$ & 130 & 300 & 150 & 60 & $\mathbf{1 . 8 6}$ \\
\hline $\mathbf{3}$ & 110 & 200 & 210 & 260 & $\mathbf{2 . 2 6}$ \\
\hline $\mathbf{4}$ & 90 & 280 & 150 & 260 & $\mathbf{2 . 2 6}$ \\
\hline $\mathbf{5}$ & 120 & 230 & 240 & 120 & $\mathbf{2 . 0 6}$ \\
\hline $\begin{array}{l}\text { Grand } \\
\text { mean }\end{array}$ & & & & & $\mathbf{2 . 1 3}$ \\
\hline
\end{tabular}

Source: Field Work 2018

Criterion Mean= 2.5

Table 6 shows a grand mean of 2.13 and a criterion mean of 2.50. Since the grand mean is less than the criterion mean, it implies that majority of the respondents agreed that compromised budget monitoring has affected budget implementation. Hence, it can be concluded that the Uduagha-led government projects in the works, housing as well as basic and secondary education sector of the 2008 to 2015 Delta State was affected by compromised budget monitoring to a low extent.

Hypothesis $3\left(\mathrm{Ho}_{3}\right)$

There is no significant relationship between compromised budget monitoring and budget implementation in Delta State.

Table 7: Chi-square analysis of questionnaire for the relationship between compromised budget monitoring and budget implementation

\begin{tabular}{|c|c|c|c|c|c|c|c|}
\hline Items & SA/A & SD/D & Total & Df & $\mathrm{X}^{2}$-cal. & $\mathrm{X}^{2}$-cri. & Decision \\
\hline 1 & 63 & 37 & 345 & \multirow{5}{*}{3} & \multirow{5}{*}{62.95} & \multirow{5}{*}{7.82} & \multirow{5}{*}{$\begin{array}{l}\mathrm{Ho}_{3} \text { is } \\
\text { Rejected }\end{array}$} \\
\hline 2 & 81 & 19 & 345 & & & & \\
\hline 3 & 61 & 39 & 345 & & & & \\
\hline 4 & 67 & 33 & 345 & & & & \\
\hline 5 & 68 & 32 & 345 & & & & \\
\hline
\end{tabular}

Source: Field Work 2018

$\mathrm{P}>0.05$

In table 7 above, with alpha level of 0.05 , the degree of freedom (DF) of 3 , the critical value is 7.82 while calculated value is 62.95 . Since the calculated value is greater than the critical value, the null hypothesis is therefore 
rejected. This means that there is a significant relationship between compromised budget monitoring and budget implementation in Delta State.

Research Question Five:

To what extent has culture of corruption affected budget implementation in Delta State?

Table 8: Mean rating of the response of sampled staff on the relationship between culture of corruption and budget implementation

\begin{tabular}{|l|l|l|l|l|l|}
\hline $\mathbf{S} / \mathbf{N}$ & $\mathbf{A}$ & SA & D & SD & X \\
\hline $\mathbf{1}$ & & 230 & 195 & 280 & $\mathbf{2 . 3 2}$ \\
\hline $\mathbf{2}$ & & 200 & 252 & 144 & $\mathbf{2 . 0 9}$ \\
\hline $\mathbf{3}$ & & 260 & 225 & 140 & $\mathbf{2 . 1 2}$ \\
\hline $\mathbf{4}$ & & 190 & 210 & 260 & $\mathbf{2 . 2 5}$ \\
\hline $\begin{array}{l}\text { Grand } \\
\text { mean }\end{array}$ & & & & & $\mathbf{2 . 2 2}$ \\
\hline
\end{tabular}

Source: Field Work 2018

Criterion Mean= 2.5

Table 8 shows a grand mean of 2.22 and a criterion mean of 2.50 . Since the grand mean is less than the criterion mean, it implies that majority of the respondents agreed that culture of corruption has affected budget implementation. Hence, it can be concluded that the Uduagha-led government projects in the works, housing as well as basic and secondary education sector of the 2008 to 2015 Delta State was affected by culture of corruption to a moderate extent.

Table 9: Chi-square analysis of questionnaire for the relationship between culture of corruption and budget implementation

\begin{tabular}{|l|l|l|l|l|l|l|l|}
\hline Items & SA/A & SD/D & Total & Df & $X^{2}$-cal. & $X^{2}$-cri. & Decision \\
\hline 1 & 61 & 39 & 345 & & & & \\
\cline { 1 - 4 } & 65 & 35 & 345 & & & & \\
\cline { 1 - 4 } & 68 & 32 & 345 & 3 & 216.42 & 7.82 & $\begin{array}{l}\mathrm{Ho}_{4} \\
\text { Rejected }\end{array}$ \\
\hline 4 & 60 & 40 & 345 & & & & \\
\hline 5 & 65 & 35 & 345 & & & & \\
\hline
\end{tabular}

Source: Field Work 2018

$\mathrm{P}>0.05$

In table 9 above, with alpha level of 0.05 , the degree of freedom (DF) of 3 , the critical value is 7.82 while calculated value is 216.42 . Since the calculated 
value is greater than the critical value, the null hypothesis is therefore rejected. This means that there is a significant relationship between culture of corruption and budget implementation in Delta State.

\section{Discussion of Results}

The study showed that there is a significant relationship between politics of accommodation and budget implementation in Delta State. This is evident to the fact the executives and legislators who are supposed to ensure that the projects in the budgets are properly and timely implemented are compromising because of politics of accommodation. This finding gives credence to Onho \& Zayol (2017) who reported that budgeting and budgetary control in the public sector is weak and has failed despite the effort of government because of political environment, non-adherence to budgetary control measures, dependence on federation account, untrained budget staff, corruption and inflation. The study is also in line with Inna (2018) who opined that factors such as late presentation and passage of appropriation bills, delay in release of funds for capital projects, ineffective planning, corruption in the public sector amongst others have contributed to low budgetary implementation in Nigeria.

The study showed that there is a significant relationship between poor commitment and budget implementation in Delta State. One plausible explanation for this finding is that budget in the public sector of Nigeria has almost become a ritual or a yearly affair which though good in content but without commensurate appreciable results. This finding is in congruence with Onyiah, Ezeamama, Ugwu and Mgbodile (2016) who reported that poor project conceptualization, design or planning practices by Ministries, ineffective planning, poor commitment and delay in release of funds for capital projects, corruption in the public sector amongst others have contributed to low budgetary implementation in Nigeria.

The study revealed that there is a significant relationship between compromised budget monitoring and budget implementation in Delta State. This finding concord with Ekhator and Chima (2015) who found that the goals of most policies were not accomplished in Nigeria due to incessant budget failure at the stage of the formulation and implementation. Critical among the factors responsible for the failure were; delay in preparation, late submission and appropriation, cumbersome bureaucratic process of securing release of funds, short fall in revenue, poor implementation plan, compromised budget monitoring and above all corruption. 
The study revealed that there is a significant relationship between culture of corruption and budget implementation in Delta State. This finding is in agreement with Ekhator and Chima (2015) who asserted that the goals of most policies were not accomplished in Nigeria due to incessant budget failure at the stage of the formulation and implementation. Critical among the factors responsible for the failure were; delay in preparation, late submission and appropriation, cumbersome bureaucratic process of securing release of funds, short fall in revenue, poor implementation plan, compromised budget monitoring and above all corruption. The study is also in consonance with Inna (2018) who asserted that factors such as corruption in the public sector, late presentation and passage of appropriation bills, delay in release of funds for capital projects, ineffective planning amongst others have contributed to low budgetary implementation in Nigeria.

\section{Methodology}

The study adopted descriptive survey research design. The use of descriptive survey design is predicated on the fact that the researcher used a questionnaire to obtain information on the variables under study from the sample that was drawn from the population. This design enables the researcher to collects detailed information that describe existing phenomena in their natural setting, make comparism and evaluation, as well as identify problems or justify current conditions and practices as well as determine what others are doing with similar problems to solutions and benefits from experience making future plans and decisions (Nwankwo 2000).

The population of the study comprised all senior staff in the Delta State Ministry of Basic and Secondary Education, Ministry of Economic Planning, Ministry of Works, Ministry of Housing and Ministry of Finance. The total populations of the Senior Staff in the five ministries are three thousand, two hundred and eighty (3208). The sample of the study consists of three hundred and fifty-five senior staff that was drawn from level ten (10) to level 16 from five (5) ministries in the Delta State Civil Service. Stratified sampling technique was used to group the staff into different departments in the ministries and then department of planning, research and statistics was selected from the five departments, department of project supervision and monitoring was selected from the ministries of works, housing and basic and secondary education. Then departments of budget and finance (Accountant General Office) were selected from the ministries of economic planning and finance. Three hundred and fifty staff were randomly selected from the two departments in all the five sampled ministries using simple random sampling 
technique. The choice of stratified is to ensure equal representation of all the ministries in the civil service. Simple random sampling technique was used based on the fact that every staff in the two sampled departments have equal chances of been selected.

The instrument that was used for data collection is budget implementation Questionnaire. The budget implementation questionnaire is made up of three sections and it contains sixteen (16) items which enabled the researcher to spread the questions/items across the independent and intervening variables. The various indicators used were based on politics of accommodation, poor budget implementation, compromised budget monitoring and the culture of corruption. The face and content validity of the budget implementation questionnaire was carried out by three experts in the department of Political Science and Public Administration. The members of the panel were given the instrument, the topic under investigation, the research questions and hypotheses needed for the validation. The members made corrections, recommendations and suggestions as appropriate. On receipt of comments, corrections were made as recommended by the panel.

The data were collected by the researcher and ten (10) research assistants. Before the commencement of data collection, the researcher and the research assistants went through the contents of the instrument to enable them understand the kind of data to collect and thus guide the respondents properly. All the respondents to the questionnaire were given a maximum of 15 minutes to respond to the items in the questionnaire. All the questionnaires were collected on the spot from the respondents immediately after 15 minutes. All the research questions were answered using mean rating. All the research hypotheses were tested for significant difference at 0.05 level of significance using Chi-Square.

\section{Conclusions and Recommendation}

The following conclusions were drawn based on the major findings of this study:

Since there is a significant relationship between politics of accommodation and budget implementation in Delta State, it is concluded that politics of accommodation has a significant negative effect on budget implementation in Delta State. Besides, in so far as there is a significant relationship between poor commitment and budget implementation in Delta State, it is concluded that poor commitment on the part of different stakeholders and departments to budget implementation has undermined budget implementation in Delta State. Also, to the extent that there is a significant relationship between 
compromised budget monitoring and budget implementation in Delta State, it is concluded that compromised budget monitoring by different departments and stakeholders in charge of budget monitoring has negatively affected budget implementation in Delta State. Finally, considering that there is a significant relationship between culture of corruption and budget implementation in Delta State, it is concluded that ingrained culture of corruption has constrained budget implementation in Delta State.

In the light of the above, approved budgets should be religiously implemented without considering or accommodating the personal or selfish interests of different stakeholders in the political system. There should also be genuine and high-level commitment to the execution of budgets after their approval so that such budgetary allocations and provisions can translate into concrete development in all the envisage sectors. In addition, an efficient and effective monitoring of approved budgetary projects should be put in place so as to ensure that they meet the standards and yearly budgetary provisions. Essentially too, there should be zero tolerance for corruption as well as an appropriate and result-oriented evaluation system and practice that will seek to compare the level of results of achievement with the stated and desired objectives.

\section{References}

Achi, S. O. 2013. "Poor Budgetary Performance: Causes and Implications for Development." European Journal of Accounting Auditing and Finance Research 1 (2): 53-66.

Adekunle, S. B. 2016. "Assessment of Factors Responsible for Budget Failure in Nigeria." Journal of Social Sciences and General Studies 4 (6): 23-29.

Adetayo, P. N. 2017. "Government Budgeting in Developing Countries." London: Free Press.

Asogwa, M. N. 0. 2015. "Measures that would Stem the Tide of low Budget Implementation in Nigeria Public Sector using South-East geopolitical Zone of Anambra, Enugu, Abia, Imo, Ebonyi and Enugu States." Journal of Policy and Development Studies 9 (2): 27-34.

Ekhator, V. E. \& Chima, P. 2015. "Budget and Implementation of Public Policy in Nigeria.” British Journal of Economics, Management \& Trade 10 (3):1-8. 
Ianna, J. G. 2018. "Budget Implementation and Governance in Nigeria." International Journal of Academic Discourse 4 (6): 1-8.

Njokwu, A. D. 2015. Assessment of the Impact of Budget Implementation in the Attainment of the Millennium Development Goals (MDGs)-Related programmes in Anambra State.

Nwankwo, O. P. 2000. Research Methods in Education and Social Sciences. Onitcha: Princewill Publishing House.

Nwaorgu, I. A. 2018. "The Effect of Dominant Individuals on Budget Implementations in Nigeria." African Research Review 9 (1): 23-29.

Oke, M. O. 2013. "Effect of Budget Implementation on the Nigerian Economic Growth." Journal of Developing Country Studies 3 (13): 34-39.

Onho, S. \& Zayol, P. 2017. "A Critical Appraisal of Budgeting and Budgetary Control in the Public Sector: A case study of Ministry of Finance, Benue State." International Journal of Scientific \& Engineering Researc 8 (1): 1725-1745.

Oniore, J. O. 2014. "Budget Implementation and Economic Development in Delta State from 1991 to 2010." International Journal of Academic Research in Business and Social Sciences 4 (3): 34-39.

Onyiah, I. A., Ezeamama, N. C., Ugwu, J. N. \& Mgbodile, C. C. 2016. Impact of Budget Implementation and Control Reforms of the Federal Government of Nigeria." British Journal of Economics, Management \& Trade 11 (2): 1-13.

Plebn, J. 0. 2009. "Public Finance and Management: Theory and Cases." Paris: Johnson Publishers.

Ugoh, C. S. \& Ukpere, W. I. 2009. "Problems and Prospects of Budgeting and Budget Implementation in local Government System in Nigeria." African Journal of Business Management 3 (12): 836-846. 